\title{
Study on Painting State Before Sketching
}

\author{
Siying Qin \\ Heihe University \\ Heihe, China 164300
}

\author{
Jialing Shao \\ Heihe University \\ Heihe, China 164300
}

\begin{abstract}
In this paper, the author studies and expounds the state of the writers' painting in oil painting. It elaborated in detail to first adjust their painting mentality when sketching. Then elaborated the painter before writing how to understand the object, how to adjust the observation method and other specific issues.
\end{abstract}

\section{Keywords—sketch; status; gnosis; observation}

\section{INTRODUCTION}

In many previous tutorials, the interpretation of oil painting sketches is basically to cut into the drawing steps at the beginning. In fact, the state of painting before painting is directly related to the success or failure of sketching. In order to be successful in painting, you must first adjust your mood. Put yourself into the sketches with a lot of enthusiasm. Next, how to adjust the painting state of oil painting is studied and expounded.

\section{AdJUSTING THE STATE OF PAINTING}

First of all, we must use our full mind to paint, that is to say, we should attach great importance to the upcoming painting journey before drawing. First of all, this emphasis is reflected in all the preparatory work done for sketching activities, such as the study of relevant theories in advance, the copying of some famous paintings, the experience of different techniques, and the massive appreciation of excellent works, both ancient and modern, and foreign, analysis of the characteristics of each artistic style. In particular, we should prepare all kinds of tools before we start, so that we can make the painting easier and everything will be in a good mood. The painting is also smooth and beautiful. If the tools are not in place, the more you draw, the worse you are. Instead of conquering the objects you want to draw, you are defeated by the painting. The painter must be confident in his heart and believe that he can do the best he can. This confidence and firmness will give you a decisive and positive artistic judgment and treatment in the process of painting, that is to say, after you have a highly valued painting mentality, you should dare paint, not flinch because you care too much. In a word, after making good preparation, with wise painting method, confident and firm belief, brave, you can certainly reach the other side of success.

Second, painting sketches should be hard to learn, perseverance. Xun $\mathrm{Zi}$ said, "If you give up, you will never bend your rotten wood. If you will never give up your perseverance, the gold and stone can be carved." This is true and true, doing things without brave, even if the rotten wood couldn't cut, and if perseverance, even hard stone would be pierced. In our sketches, with a steadfast attitude to practice, there is no insurmountable difficulty. For example, some students, neither late for class nor absenteeism, it seems to work very hard every day, in fact, do a day monk hit a day clock, unable to work, this is the expression of bad painting mentality. We need to remember Darwin's words: "The opportunity is everyone, but many don't know they've met it ."

\section{OBSERVATION, EXPERIENCE, GNOSIS}

After setting a good painting mentality, we can begin the physical sketch of the substance. At the beginning of the sketch, our first task is to observe, and this is also an important step that some people ignore when sketching. In the art and visual perception, Arnheim, the American scientist, said, "if our eyes are the father, then the hand is the mother, and the creation of the art works highly by the eye and the hand." Observation of this sketch if it can be valued, and put into practice, then basically laid the foundation for success. Some people say: "details determine success or failure." Careful observation is the most important detail that determines whether the painting is moving in the right direction.

\section{A. Methods of Observation}

First contact with the image, we are more excited, without hesitation, up the easel on the start. Initiated at the beginning of the beginning dare to boldly go, always better than thinking too timid without drawing, impulse can make the person to act directly, this is not a bad thing, even some unexpected wonderful brushwork. However, in this blind observation, no thinking out of the painting, will lack a sense of unity, sense of theme, sense of belonging, even if there is a brilliant moment, it must be fragmented. This broken and wonderful intertwined can neither stabilize the picture nor complete the shape, let alone dominate the overall situation, but is a mob, making the picture unstructured. Therefore, if the painting is not based on the whole observation, the result will lead to the more passive the painting and the final failure. How to observe oil painting scientifically? First, we should understand the observation method of painting.

We cannot avoid using such observation methods, such as holistic observation, centralized observation, scattered observation and impression observation.

1) Holistic observation: To observe the painting object in a macroscopic, overall, comparative, scientific, associated angle of view. Through the overall observation can build the structure of the picture, mobilize and organize various 
components. In the process of sketching, we should consider the integration of various relations caused by various factors, which is what we often call "holistic observation" and "overall description". The whole observation is to carry out the main and imaginary artistic treatment on the picture, and then render the atmosphere and the theme.

2) Centralized observation: The method of concentrated observation of points of interest, and concentrated observation is based on the whole observation, using excitatory points as clues to extract the subject matter of interest to oneself, just like the focus perspective method in photography, which is a bit clear and the rest is vague. We need to apply a bit of observation when we go into detail.

3) Scatter observation method: It is a moving line of sight observation like a shake-shaking mirror, and can even be observed around the object image. The scattered point observation is used to compare the pictures, that is, the multipoint observation comparison method.

4) Impression observation method: It is a kind of observation method of subjective memory, mainly about the observation of memory and subjective consciousness, such as observation and memory of inherent color, subjective judgment of inherent color, analysis and understanding of conditional color. In fact, the observation of conditional color is an extension of the whole observation method.

In fact, in oil painting, these four methods are always used comprehensively. The correct observation method is to take the whole observation as the main method, which runs through the whole sketch process, and at the same time, it is supplemented by a concentrated observation method on the description of the subject details. Then through the scattered points of comparative observation, it enters into the memory and subjective dynamic observation stage. Overall observation is the most important because even when we use concentrated observation to depict local details we must always maintain a relatively holistic concept of sketching.

\section{B. Observation Steps}

Before we do the composition of oil painting, we must first make a macroscopic, holistic, comparative, scientific, and related observation of the object you are going to paint and the related components around it.

Step 1: Feel the atmosphere. Through the first intuition of freshness, observe the whole field of vision to draw large breath. This step sets the tone of sketching, such as being passionate, lyrical, quaint, thick, abstract or intentional, etc.

Step 2: experience the excitement. That is to say, after the first observation, we can find out the interest in the picture, such as the beauty of the image, the sense of structure, or the sense of light and so on.

Step 3: ignore colors. Observe the black and white gray relation of the objects in the field of vision, and determine the frame of black and white gray layout with large screen.

Step 4: observe the relationship and basic trend of the point line between the object image and the surrounding object. The purpose of this step is to organize, integrate and coordinate the specific components of the picture, so that its priorities are appropriate, void and real, and organically combined.

Step 5: contrast the theme. Selective observation of the main objects, such as the situation, proportion or mental outlook, etc.

Step 6: observe the color tone. Such as: cool color, warm color, contrast color, coordinated color, etc., integrated tone.

\section{Experience and Perception}

Before painting sketches, it is also important to experience and realize sincerely before painting. At the beginning of the sketch, the painter will have some impulse, so be bold to experience, let the passion be fully released, even if the experience of failure, it is also a prelude to success. It is important to understand that you are not a tourist, but a truthful party When sketching carefully experience, sincere feeling, abandon superficial, full of feelings brewing, with the most sincere heart to understand the experience of the physical image that we bring that natural move, Truly realize the expression of the special features and connotations contained in the object image. For example: each person has its own life track, has its own emotional characteristics. Some images reveal a vibrant vitality; some give a tender and delicate emotional expression; some are a force and a shock; some are the vicissitudes of time; others may be an interpretation of thought or a dialogue of the soul.

Only through careful experience can we feel the breath transmitted by the image and capture and depict the essence of the image. Only by carefully observing the aura of the picture and appreciating the language used behind the image can you devote all your energy to your sincerity and feelings, so that the image you draw will have the quality and track of life that belongs to it. At the same time, there is a real vitality, you draw the image of the meaning of life has been realized. At the same time, this visceral emotion forces you to subconsciously decide which style of writing you should use. That is a valuable and meaningful stroke, which is subordinate to the whole macro control.

\section{CONCLUSION}

Through a lot of sketching practice, it can be concluded that we must enter a good state of painting before sketch of oil painting. Only after the preparations for the full state of mind and the preparation of the objective hardware conditions, we can feel just like a fish in water when sketching and complete the work with ease. First of all, we must pay attention to each painting from the depths of thought and actively adjust the state of painting before we start. Every painter should treat the sketching activities with care, and paint with full mentality. This kind of mentality painting will make us do a lot of preparation for each sketch, and then lay a solid foundation for follow-up work. With the mental preparation for painting the picture well, we must carefully observe, experience, and feel before we sketch. Through the overall careful observation and perception, we can build a large frame and artistic effect in the heart, which can create a tone for the sketching work and provide the guiding principles for the whole painting process. 
Only by attaching great importance to the preparations for the state before the oil painting, can we create a high-quality sketching work. Therefore, the author hopes that the research results can provide some help and inspiration for the painters who are engaged in artistic creation.

\section{REFERENCES}

[1] Dai Shihe. Da Shihe And His Notes In Three Years [M]. Guangxi Fine Arts Press.2005 戴士和. 戴士和笔记三年集[M].广西美术出版社, 2005.

[2] Chang Ruilun. Painting Composition [M]. People's Art Press, 2010. 常 瑞伦.绘画构图学 [M].人民美术出版社, 2010 .

[3] Ian Roberts. Art Of Composition [M]. Shanghai People's Art Press, 2012. 伊恩.罗伯茨.构图的艺术 $[\mathrm{M}]$.上海人民美术出版社,2012.

[4] Zheng Guangxu. Brickwork [M]. Beijing: People's Art Press.2013 郑光 旭.点画砌构[M].北京：人民美术出版社.2013. 